\title{
Single Versus Multiple Doses of Surfactant Treatment in Preterm Infants
}

\author{
(1) Betül Siyah Bilgin, (1) Özge Altun Köroğlu, (1) Demet Terek, (1) Mehmet Yalaz, (1) Mete Akisu, \\ (1) Nilgün Kültürsay \\ Ege University Faculty of Medicine, Department of Pediatrics, Division of Neonatology, İzmir, Turkey
}

\begin{abstract}
Aim: Exogenous surfactant may be needed not only for Respiratory Distress syndrome (RDS) treatment; but also, in the management of other pulmonary diseases of infants. In this study, we aimed to investigate the impact of single versus multiple doses of surfactant therapy in pulmonary problems of preterm infants.

Materials and Methods: In this study, preterm infants who needed surfactant treatment were retrospectively evaluated. Surfactant therapy for RDS were given as $200 \mathrm{mg} / \mathrm{kg}$ poractant or $100 \mathrm{mg} / \mathrm{kg}$ beractant and repeated with $100 \mathrm{mg} / \mathrm{kg}$ doses when needed later. Poractant or beractant $(100 \mathrm{mg} / \mathrm{kg})$ were given in the treatment of other pulmonary diseases.

Results: Totally 64 preterm patients were recruited into this study. Patients in group 1 (43.8\%) received a single dose of surfactant; whereas group 2 patients (56.2\%) had more than one dose. Mean gestational age and birth weight of infants in group 2 were significantly lower than group $1(p<0.05)$. Intrauterine growth restriction (IUGR) was more common in group 2 ( $p=0.041)$. Multiple doses of surfactant were needed for severe RDS, atelectasis, pulmonary hemorrhage and pneumonia. Duration of mechanical ventilation and hospitalization were longer in group 2 ( $p<0.05)$. Mortality rates were higher in group 2 ( $p=0.011)$.

Conclusion: Preterm infants with earlier gestational age and lower birth weight; particularly with IUGR may need multiple doses of surfactant due to more severe respiratory problems regardless of antenatal steroid or maternal chorioamnionitis status. Duration of mechanical ventilation, hospitalization and also neonatal mortality remained higher due to disease severity in preterms who needed multiple doses of surfactant.
\end{abstract}

Keywords: Preterm, respiratory distress syndrome, atelectasis, pulmonary hemorrhage, pneumonia

\section{Introduction}

In 1959, Avery et al. (1) showed that a deficiency of surface-active material (surfactant) may be significant in the pathogenesis of hyaline membrane disease in preterm infants. Exogenous surfactant was first used in Respiratory Distress syndrome (RDS) treatment by Fujiwara et al. (2) in
1980. Exogenous Surfactant increases the lung compliance and functional residual capacity at expiration, provides homogenous gas distribution at inspiration and increases oxygenation and survival in RDS patients (3).

Exogenous surfactant is now also used in many clinical situations, other than RDS, which cause endogen surfactant

This work has been presented in e-poster session at European Academy of Paediatrics Congress (EAPS 2016) , Geneva/Switzerland, between 21-25 October. 
dysfunction or inactivation such as pulmonary hemorrhage, pneumonia, Meconium Aspiration syndrome, acute lung injury, bronchopulmonary dysplasia (BPD) or congenital diaphragmatic hernia (4). Single or multiple doses of surfactant may be needed not only for RDS treatment; but also for other indications in the management of sick newborns. The impact of multiple doses of surfactant on morbidity and mortality is not clearly known. When single or multiple doses of surfactant replacement in RDS are compared, pneumothorax and death rates are found to be lower in the latter (5). In this study, we aimed to investigate the impact of single versus multiple doses of surfactant therapy in sick preterm infants.

\section{Material and Methods}

\section{Study Design}

In this study, preterm infants ( $\leq 366 / 7$ weeks), born between July 2011- June 2012, who needed surfactant due to neonatal pulmonary problems in Ege University Neonatal Intensive Care Unit were retrospectively evaluated. This study was approved by the Ege University Faculty of Medicine Clinical Research Ethics Committee (approval number: 11-12.2/4). Informed consent of the parents of the study subjects were obtained.

\section{Clinical Data}

Antenatal risk factors such as multiple gestation, antenatal corticosteroids, maternal age, premature rupture of membranes, chorioamnionitis and neonatal characteristics such as gestational age (according to last menstrual period), birthweight, intrauterine growth [based on the growth curve of Lubchenco et al. (6)], gender, mode of delivery, apgar scores and clinical progress were recorded. Definition of intrauterine growth restriction (IUGR) was based on a series of prenatal weight evaluations showing a decrease in weight percentiles.

Diagnostic criteria for the diagnosis of lung diseases were as follows:

Respiratory distress syndrome: Existence of clinical findingsofrespiratorydistress (tachypnea, grunting, cyanosis, retractions), need for oxygen and/or positive pressure ventilation and typical $\mathrm{X}$-ray findings (reticulogranular pattern, decreased aeration, air bronchograms, ground glass) and an absence of suspicious or proven findings of infection (7).

Atelectasis: Based on X-ray findings.

Pulmonary hemorrhage: Bloody aspirate from endotracheal tube with at least one of the following: micro lobular infiltrates in chest X-Ray, increase in mechanical ventilation support, more than 0.3 increase in the fraction of inspired oxygen from basal level or an acute decrease of hematocrit (>10\%) (8).

Congenital pneumonia: Clinical findings of respiratory distress, need for oxygen and/or mechanical ventilation support, extrapulmonary clinical signs of sepsis starting from birth and typical chest X-ray findings with suspicious or proven infection (maternal chorioamnionitis, maternal urinary tract infections, increased or decreased leukocyte count or serum C-reactive protein increase and positive blood or endotracheal aspirate cultures) on the first day of life (7).

Bronchopulmonary dysplasia: The severity of disease was determined according to the need for oxygen support at postnatal $28^{\text {th }}$ day and the need for oxygen/positive pressure ventilation at term (9).

Surfactant treatment was administered as described in the European Consensus Guidelines and the American Academy of Pediatrics (10). Surfactant preparations were chosen according to the clinical teams' decisions as beractant or poractant. Prophylactic or rescue surfactant therapy for RDS was given as $200 \mathrm{mg} / \mathrm{kg}$ poractant or $100 \mathrm{mg} / \mathrm{kg}$ beractant and later repeated with $100 \mathrm{mg} / \mathrm{kg}$ doses. $100 \mathrm{mg} / \mathrm{kg}$ poractant or beractant were given for other pulmonary diseases. For patients who developed atelectasis, pulmonary lavage was carried out with $50 \mathrm{mg} /$ $\mathrm{kg}$ surfactant diluted to four-fold saline $(5 \mathrm{mg}$ phospholipid/ $\mathrm{mL}$ ). Treatment was administered slowly in aliquots of 2.5 $\mathrm{mL}$ (11).

Prophylactic surfactant therapy was performed for all infants who were born at less than 26 weeks of gestation, with the INSURE (Intubate-SURfactant-Extubate to CPAP) technique and to preterm infants with gestational age $<30$ weeks who needed intubation in the delivery room within 15 minutes of birth (10). Preterm infants who did not have prophylactic surfactant in the delivery room were given rescue surfactant therapy within the first six hours if their $\mathrm{FiO}_{2}$ value was $>0.40$ and arterial-to-alveolar oxygen tension ratio was $\left(a / A \mathrm{PO}_{2}\right)<0.2$. Response to surfactant replacement therapy was evaluated by arterial blood gas analysis (at $2^{\text {nd }}$ and $6^{\text {th }}$ hours of surfactant replacement therapy) and chest $\mathrm{X}$-ray (at $6^{\text {th }}$ hour of surfactant replacement therapy). Surfactant replacement therapy was repeated at a maximum of three doses, if the findings of RDS persisted after six hours from initial surfactant treatment (10). In the treatment of other pulmonary diseases, surfactant replacement was considered when $\mathrm{FiO}_{2}$ 
was $>0.40$ and arterial-to-alveolar oxygen tension ratio $\left(\mathrm{a} / \mathrm{APO}_{2}\right)$ was $<0.2$.

At the retrospective follow-up; patients were assigned into two groups according to their surfactant replacement status: Group 1 consisted of patients who received a single dose of surfactant; and group 2 consisted of patients who received multiple doses of surfactant. Presence of pneumothorax, intraventricular hemorrhage, patent ductus arteriosus and chronic lung disease, duration of mechanical ventilation and hospitalization, the need for postnatal steroids and mortality were recorded. With regard to surfactant replacement treatments; indications, timing and total number of applications were followed up in addition to blood gas analyses and a/A $\mathrm{PO}_{2}$ ratios.

\section{Statistical Analysis}

SPSS 17.0 software was used for statistical analyses. For comparison of groups; chi-square test was used for categorical data and Mann-Whitney $U$ test was used as a nonparametric test. $P$ values $<0.05$ were considered statistically significant.

\section{Results}

For the whole study group of 64 infants, the mean gestational age was $28.37 \pm 3.00$ (23-36) weeks; mean birth weight was $1.238 \pm 609$ (580-2.950) grams, mean number of surfactant therapy applications was $2.29 \pm 1.59$ (1-6).

The demographic characteristics of the study group are given in Table 1. The indications of surfactant treatment and the rate of single versus multiple doses are given in Table 2.

Twenty-eight patients $(43.8 \%)$ (Group 1 ) received a single dose of surfactant; whereas the remaining 36 (56.2\%) (Group 2) patients needed multiple doses. The mean gestational age and birth weight of those infants in group 2 were significantly lower than group 1 ( $p$ values $<0.05$ ). IUGR was more common in group $2(p=0.041)$; however other clinical characteristics such as gender, multiple gestation, antenatal corticosteroids, premature rupture of membranes or chorioamnionitis did not differ between the groups (Table 1).

Multiple doses of surfactant were needed for severe RDS, atelectasis pulmonary hemorrhage, and pneumonia (Table 2). Surfactant lavage treatment was performed for nine preterm infants in the treatment of atelectasis and radiological recovery was observed in seven (77.7\%) of them. The duration of mechanical ventilation and hospitalization were longer in group 2 (all p values $<0.05$ ). Mortality rates were higher group $2(p=0.011)$ (Table 3$)$.

\section{Discussion}

Exogenous surfactant is used in the treatment of many clinical conditions other than RDS such as pneumonia, Meconium Aspiration syndrome, newborn pneumonia, genetic deficiency of surfactant, acute lung damage, resistant pulmonary hypertension, BPD or congenital diaphragmatic hernia in the neonatal period (4). These diseases usually show endogenous surfactant dysfunction or inactivation or structural deficiency. Plasma proteins, erythrocyte, meconium, cytokine and other inflammatory products, proteases or reactive oxygen species may disrupt surfactant synthesis and structure.

A single dose of surfactant was given to 28 patients and multiple doses were given to 36 patients for the treatment of RDS in our study. Patients who needed multiple surfactant doses had lower birthweight and

Table I. Demographic characteristics of study population

\begin{tabular}{|c|c|c|c|c|}
\hline & All patients $(n=64)$ & Group 1 (Single dose) $(n=28)$ & Group 2 (Multiple doses) $(n=36)$ & $\mathbf{p}$ \\
\hline Gestational age, weeks ${ }^{a}$ & $28.4 \pm 3.0$ & $29.2 \pm 3.1$ & $27.7 \pm 2.7$ & 0.048 \\
\hline Birth weight, gram ${ }^{a}$ & $1.238 \pm 609$ & $1.439 \pm 650$ & $1.082 \pm 532$ & 0.019 \\
\hline Male gender & $39(60.9 \%)$ & $16(57.1 \%)$ & $23(63.9 \%)$ & 0.615 \\
\hline Cesarean & $46(71.9 \%)$ & $21(75 \%)$ & $25(69.4 \%)$ & 0.781 \\
\hline IUGR & $15(23.4 \%)$ & $3(10.7 \%)$ & $12(33.3 \%)$ & 0.041 \\
\hline Apgar $1^{\text {st }}$ min $^{\text {a }}$ & $3.8 \pm 2.1$ & $4.4 \pm 2.2$ & $3.4 \pm 1.9$ & 0.074 \\
\hline Multiple birth & $17(26.6 \%)$ & $7(25.0 \%)$ & $10(27.8 \%)$ & 1.00 \\
\hline ANCS & $46(71.9 \%)$ & $22(78.6 \%)$ & $24(66.7 \%)$ & 0.403 \\
\hline PROM & $12(18.8 \%)$ & $6(21.4 \%)$ & $6(16.7 \%)$ & 0.750 \\
\hline Chorioamnionitis & $3(4.7 \%)$ & 0 & $3(8.3 \%)$ & 0.250 \\
\hline
\end{tabular}


earlier gestational age. In the limited number of previous studies, application of multiple doses was found to be more effective on oxygenation with a tendency to decrease mortality rates as well as pneumothorax risk (RR 0.51; 95\% Cl 0.30-0.88) (5,12). Multiple doses of surfactant were reported to be needed more commonly in more extreme preterm infants, infants with very low birthweight and in cases with maternal chorioamnionitis (13). The European Consensus Guidelines on the management of RDS recommends that if RDS findings continue (such as oxygen and mechanic ventilation need) secondary or sometimes tertiary surfactant applications should be used (14). In our study, multiple doses of surfactant were given to those infants with severe RDS due to lung immaturity.

In this study, preterm infants with IUGR required a significantly higher number of doses of surfactant therapy. Results of studies on IUGR's impact on RDS severity vary greatly (15-19). In one study conducted by Peacock et al. (15) respiratory system morbidities of small for gestational age

Table II. Indications for surfactant replacement therapy

\begin{tabular}{|l|l|l|l|}
\hline & $\begin{array}{l}\text { All patients } \\
(\mathbf{n = 6 4 )}\end{array}$ & $\begin{array}{l}\text { Group 1 } \\
\text { (Single dose) } \\
(\mathbf{n = 2 8 )}\end{array}$ & $\begin{array}{l}\text { Group 2 } \\
\text { (Multiple } \\
\text { doses) } \\
(\mathbf{n = 3 6})\end{array}$ \\
\hline RDS & 62 & 27 & 35 \\
\hline Atelectasis & 9 & 0 & 9 \\
\hline $\begin{array}{l}\text { Pulmonary } \\
\text { hemorrhage }\end{array}$ & 8 & 0 & 8 \\
\hline Pneumonia & 4 & 1 & 3 \\
\hline Total & 83 & 28 & 55 \\
\hline
\end{tabular}

a: Patients who received surfactant therapy due to atelectasis and pulmonary hemorrhage were all previously given surfactant therapy for RDS. Two patients who had multiple doses of surfactant therapy due to pneumonia had also received surfactant therapy for RDS previously, RDS: Respiratory distress syndrome
(SGA) and appropriate for gestational age (AGA) infants who were born under 1.000 grams were compared and no difference in surfactant quantity was found. Similarly, Bartels et al. (16) found the RDS percentage in AGA and SGA groups to be equal. However, Spinillo et al. (17) reported a significantly increased risk of RDS in preterm infants with IUGR. Chronic lung disease is reported to be more common in the SCA group compared to AGA preterms (18). Preterm IUGR infants have a higher pulmonary morbidity risk and therefore they may need more doses surfactant treatment than the AGA infants within the same age range (19).

Pulmonary hemorrhage may be another indication for multiple doses of surfactant treatment. Prematurity, IUGR, patent ductus arteriosus, respiratory problems, mechanical ventilation and surfactant treatment are risk factors for pulmonary hemorrhage (20). Hemoglobin, erythrocyte, membrane lipids and serum proteins disrupt the function of surfactant, hence, surface tension increases and secondary RDS develops (21). There is no randomized study showing the impact of surfactant's administration in pulmonary hemorrhage treatment. Most of the studies on this issue are based on observations. It has been shown that exogenous surfactant application improves oxygenation in the supportive treatment of pulmonary hemorrhage in the short term, however, no long-term benefit has been found. Pandit et al. (22) showed an improvement in oxygenation indexes after surfactant administration when they evaluated cases of pulmonary hemorrhage retrospectively. Analyzing the associated factors of surfactant dysfunction of 27 babies who had pulmonary hemorrhage and edema, Amizuka et al. (23) reported that exogenous surfactant application may overcome surfactant inhibition, and this may be an adjuvant treatment that solves respiratory problems. Aziz and Ohlsson (24) did not come to a conclusion about this treatment in their meta-analyses published in 2008.

Table III. Clinical outcome of study groups

\begin{tabular}{|c|c|c|c|c|}
\hline & $\begin{array}{l}\text { All patients } \\
(n=64)\end{array}$ & $\begin{array}{l}\text { Group } 1 \\
\text { (Single dose) }(n=28)\end{array}$ & $\begin{array}{l}\text { Group } 2 \\
\text { (Multiple doses) }(n=36)\end{array}$ & $\mathbf{p}$ \\
\hline NEC & $27(42.2 \%)$ & $7(25 \%)$ & $20(55.6 \%)$ & 0.028 \\
\hline $\mathrm{ICH}$ & $14(21.8 \%)$ & $4(14.3 \%)$ & $10(27.8 \%)$ & 0.322 \\
\hline ROP & $19(29.7 \%)$ & $5(17.9 \%)$ & $14(38.9 \%)$ & 0.121 \\
\hline BPD & $21(32.8 \%)$ & $4(14.3 \%)$ & $17(47.2 \%)$ & 0.007 \\
\hline Duration of mechanical ventilation, days & $27.74(44.47)$ & $10.75(13.20)$ & $42.02(55.85)$ & 0.002 \\
\hline Duration of hospitalization, days ${ }^{a}$ & $55.91(39.19)$ & $43.04(30.74)$ & $75.60(41.87)$ & 0.004 \\
\hline Mortality & $18(28.1 \%)$ & $3(10.7 \%)$ & $15(41.7 \%)$ & 0.011 \\
\hline
\end{tabular}


Plasma proteins and cytokines in the neonatal pneumonia exudate may also inactivate surfactant. Surfactant treatment in B group streptococcus pneumonia has reduced the reproduction of bacteria and improved lung functions in animal experiments (25). Improvement was reported in the gas exchange with surfactant treatment in group B Streptococcus pneumonia in The Collaborative European Multicenter Study Group study. However, response to surfactant treatment is slower than RDS treatment and needs more repetitive doses (26). In the study conducted by Alkan et al. (27), surfactant treatment except for RDS, was mostly given to patients who were diagnosed with pneumonia in the newborn period with the longest survival time. The quantity of dose was not given in this study and the average gestational week was 35.6 weeks (27). Gortner et al. (28) gave surfactant to 15 extremely low birth weigh cases with congenital pneumonia. Although the fraction of inspired oxygen $\left(\mathrm{fiO}_{2}\right)$ need decreased initially, it rose to its former state within 12 hours. A maximum of four doses were given. One surfactant dose was given to six cases and multiple surfactant doses (up to 4) were administered to nine cases (28). In our study, four cases with congenital pneumonia were given surfactant. One patient needed one dose; while three others were given multiple doses of surfactant. Therefore, we think that preterm infants with congenital pneumonia may need multiple dose surfactant treatment due to surfactant inactivation. Future controlled studies are required to research the impacts of surfactant treatment of congenital pneumonia.

In this study, diluted surfactant lavage was performed for the nine mechanically ventilated preterm patients with atelectasis in their chest X-ray and low a/A $\mathrm{PO}_{2}$ values. Those infants had already been given surfactant treatment for RDS or other pulmonary problems. After surfactant lavage radiologic, clinical improvement was observed in seven patients (77\%). Atelectasis may develop in preterm infants under mechanical ventilation due to primary or secondary surfactant deficiency, an increase in inflammatory mediators or a decrease in mucociliary clearance. Surfactant lavage treatment may be considered for infants who develop atelectasis during mechanical ventilation. The objective of surfactant lavage is to remove the inflammatory mediators, to clear away the mucous material with lavage and to replace the inactivated surfactant. Krause et al. (29) reported a 65\% improvement in atelectasis by giving diluted surfactant with bronchoalveolar lavage followed by dornase alfa to four infants diagnosed with atelectasis after respiratory syncytial virus pneumonia.
The limitations of our study are as follows: being single centered, the small number of patients included in the study and the changes in surfactant application policies over time in RDS treatment due to the nature of this retrospective study.

The frequency of ROP (retinopathy of prematurity) and $\mathrm{ICH}$ (Intracranial hemorrhage), in terms of the morbidities seen in preterm infants, was not different among the groups who received single-dose or multiple-dose surfactant treatment; but NEC (Necrotizing enterocolitis) and BPD were more frequent in the multiple-dose surfactant treatment group. Multiple doses of surfactant decrease the NEC and mortality rate in RDS treatment (5). In our study, NEC and mortality rates were found to be higher in preterm patients who needed multiple doses of surfactant treatment. However, infants who were given multiple doses of surfactant had lower birthweight, earlier gestational age, longer time spent in mechanical ventilation, longer hospitalization and higher BPD and mortality rates than infants who needed only one surfactant dose.

\section{Conclusion}

Multiple doses of surfactant were needed in the treatment of RDS, atelectasis pulmonary hemorrhage and pneumonia in preterm patients with a low gestational age and birthweight; and also for those being IUGR regardless of antenatal steroid or chorioamnionitis status. The duration of ventilation, hospitalization and rates of BPD and neonatal mortality were higher due to disease severity in patients who needed multiple doses of surfactant.

\section{Ethics}

Ethics Committee Approval: This approval was received from Ege University Faculty of Medicine Clinical Research Ethics Committee (approval no: 11-12.2/4, date: 12.01.2012).

Informed Consent: Informed consent of the parents of the study subjects were obtained.

Peer-review: Externally peer-reviewed.

Authorship Contributions

Surgical and Medical Practices: B.S.B, D.T., Concept: N.K., M.Y., Design: N.K., M.A., Data Collection or Processing: B.S.B, D.T., Analysis or Interpretation: Ö.A.K., Literature search: B.S.B., Ö.A.K., Writing: B.S.B., Ö.A.K.

Conflict of Interest: The authors have no conflicts of interest relevant to this article to disclose.

Financial Disclosure: The authors have no financial relationships relevant to this article to disclose. 


\section{References}

1. Avery ME, Mead J. Surface properties in relation to atelectasis and hyaline membrane disease. Am J Dic Child 1959;97:517-23.

2. Fujiwara $T$, Maeta $H$, Chida S, Morita T, Watabe $\mathrm{Y}$, Abe T. Artificial surfactant therapy in hyaline-membrane disease. Lancet 1980;12:55-9.

3. Suresh GK, Soll RF. Overview of surfactant replacement therapies. I Perinatol 2005;25:40-4.

4. Kültürsay $N$, Uygur Ö, Yalaz M. The use of surfactant in the neonatal period-the known aspects, those still under research and those which need to be investigated further. Turk Pediatri Ars 2014;49:1-12.

5. Soll R, Ozek E. Multiple versus single doses of exogenous surfactant for the prevention or treatment of neonatal respiratory distress syndrome. Cochrane Database Syst Rev 2009;1:CD000141.

6. Lubchenco LO, Hansman C, Boyd E. Intrauterine growth in length and head circumference as estimated from live births at gestational ages from 26 to 42 weeks. Pediatrics 1966;37:403-8.

7. Hamvas A. Pathophysiology and management of respiratory distress syndrome. In: Martin RJ, Fanaroff AA, Walsh MC (eds). Fanaroff and Martin's Neonatal- Perinatal Medicine (9th ed). Vol. 1. St. Louis: Elsevier Mosby; 2011:1106-16.

8. Lin $\mathrm{TW}, \mathrm{Su} B \mathrm{H}$, Lin $\mathrm{HC}$, et al. Risk factors of pulmonary hemorrhage in very-low-birth-weight infants: a two-year retrospective study. Acta Paediatr Taiwan 2000;41:255-8.

9. Jobe $\mathrm{AH}$, Bancalari E. Bronchopulmonary dysplasia. Am J Respir Crit Care Med 2001;163:1723-9.

10. Sweet DG, Carnielli V, Greisen G, et al; European Association of Perinatal Medicine. European Association of Perinatal Medicine. European consensus guidelines on the management of neonatal respiratory distress syndrome in preterm infants - 2010 update. Neonatology 2010;97:402-17.

11. Gadzinowski J, Kowalska K, Vidyasagar D. Treatment of MAS with PPHN using combined therapy: SLL, bolus surfactant and iNO. J Perinatol 2008;28:56-66.

12. Dunn MS, Shennan AT, Possmayer F. Single- versus multipledose surfactant replacement therapy in neonates of 30 to 36 weeks' gestation with respiratory distress syndrome. Pediatrics 1990;86:564-71

13. Tsakalidis C, Giougki E, Karagianni P, Dokos C, Rallis D, Nikolaidis $\mathrm{N}$. Is there a necessity for multiple doses of surfactant for respiratory distress syndrome of premature infants? Turk I Pediatr 2012;54:368-75.

14. Sweet DG, Carnielli V, Greisen G, et al. European Consensus Guidelines on the Management of Respiratory Distress Syndrome - 2016 Update. Neonatology 2017;111:107-25.
15. Peacock JL, Lo JW, D'Costa W, Calvert S, Marlow N, Greenough A. Respiratory morbidity at follow-up of small-for-gestationalage infants born very prematurely. Pediatr Res 2013;73:457-63.

16. Bartels DB, Kreienbrock L, Dammann O, Wenzlaff P, Poets CF. Population-based study on the outcome of small for gestational age newborns. Arch Dis Child Fetal Neonatal Ed 2005;90:53-9.

17. Spinillo A, Capuzzo E, Piazzi G, Baltaro F, Stronati M, Ometto A. Significance of low birthweight for gestational age among very preterm infants. Br J Obstet Gynaecol 1997;104:668-73.

18. Soudée S, Vuillemin L, Alberti C et al. Fetal growth restriction is worse than extreme prematurity for the developing lung. Neonatology 2014;106:304-10.

19. Malhotra A, Sasi A, Miller SL, Jenkin G, Polglase GR. The Efficacy of Surfactant Replacement Therapy in the Growth-Restricted Preterm Infant: What is the Evidence? Front Pediatr 2014;2:118.

20. Finlay ER, Subhedar NV. Pulmonary haemorrhage in preterm infants. Eur / Pediatr 2000;159:870.

21. Holm BA, Notter RH. Effects of hemoglobin and cell membrane lipids on pulmonary surfactant activity. I Appl Physiol 1987;63:1434e42.

22. Pandit PB, Dunn MS, Colucci EA. Surfactant therapy in neonates with respiratory deterioration due to pulmonary hemorrhage. Pediatrics 1995:95:32-6.

23. Amizuka T, Shimizu H, Niida Y, Ogawa Y. Surfactant therapy in neonates with respiratory failure due to haemorrhagic pulmonary oedema. Eur J Pediatr 2003;162:697-702.

24. Aziz A, Ohlsson A. Surfactant for pulmonary hemorrhage in neonates. Cochrane Database Syst Rev 2008;CD005254.

25. Finer NN. Surfactant use for neonatal lung injury: beyond respiratory distress syndrome. Paediatr Respir Rev 2004;5 Suppl A:S289-97.

26. Herting E, Gefeller O, Land M, et al. Surfactant treatment of neonates with respiratory failure and group B streptococcal infection. Members of the Collaborative European Multicenter Study Group. Pediatrics 2000;106:957-64.

27. Alkan S, Ozer EA, Ithan O, Sutcuoglu S, Tatli M. Surfactant treatment for neonatal respiratory disorders other than respiratory distress syndrome. I Matern Fetal Neonatal Med 2015;28:131-3.

28. Gortner L, Pohlandt F, Bartmann P. Effect of a bovine surfactant in very low birth weight premature infants with congenital pneumonia. Monatsschr Kinderheilkd 1990;138:274-8.

29. Krause MF, Ankermann T. Bronchoscopic interventions with surfactant and recombinant human deoxyribonuclease for acute respiratory distress syndrome-type respiratory syncytial virus-pneumonia in moderately preterm infants: Case series. SAGE Open Med Case Rep 2014:8;2:2050313X14554479. 